\title{
Introduction to Digital Platforms and Global Law: Work Plan
}

Digital platforms are hardware or software structures that provide technological services and tools, programs and applications for the distribution, management and creation of free or paid digital content and services, including through the integration of multiple media (integrated digital platforms).

Various authors have investigated the topic of digital platforms, from the standpoint of substantive law. In particular, it is discussed whether the instruments of competition law and regulation are adequate to regulate an evolving phenomenon that transcends the classic framework of the transnational company. However, the research found in the literature is apparently not systematic, as it focuses on specific aspects (the relationships with competition law, ${ }^{1}$ with the protection of personal data, ${ }^{2}$ with copyright and intellectual

1 A. Ezrachi, M. Stucke (2016), Virtual Competition. The Promise and Perils of the Algorithm-Driven Economy, Harvard University Press (in particular 56-81); id. (2017), Artificial intelligence \& collusion: when computers inhibit competition, University of Illinois Law Review, 2017, 1175 et seq.; E. Calvano, G. Calzolari, V. Denicolò, S. Pastorello (2019), Algorithmic pricing: what implications for competition policy?, Review of Industrial Organization, 55(1), 155-171; A. Deng (2018), What do we know about algorithmic tacit collusion?, Antitrust, 33(1), 88 et seq.; M. Maggiolino (2018), I Big Data e il Diritto Antitrust, Diritto dell'economia; S. Mannoni, G. Stazi (2018), Is Competition A Click Away? Editoriale Scientifica; OECD (2017), Algorithms and Collusion. Competition Policy in the Digital Age, 39-40; OECD, Big Data: bringing competition policy to the digital era, Background note by the Secretariat, DAF/ COMP(2016)14, 29-30.

2 O. Lynskey (2017), Aligning data protection rights with competition law remedies? The GDPR right to data portability, European Law Review, 42, 793 et seq.; I. Graef, M. Husovec, N. Purtova (2018), Data portability and data control: lessons for an emerging concept in EU law, German Law Journal, 19(6), 1359 et seq.; I. Graef (2016), EU Competition Law, Data Protection and Online Platforms: Data as Essential Facility, Wolters Kluwer; J. Polonetsky, O. Tene (2013), Privacy and Big Data: making ends meet, Stanford Law Review Online, 66, 25 et seq.; J. Lerman (2013), Big Data and its exclusions, Stanford Law Review Online, 66, 55 et seq.; M. Corrales, M. Fenwick, N. Forgó (eds) (2017), New Technology, Big Data and the Law, Springer; A. Waldman (2018), Privacy as Trust: Information Privacy for an Information Age, Cambridge University Press. 
property, ${ }^{3}$ with the foundations of democracy, ${ }^{4}$ and with global governance. ${ }^{5}$

The lack of effectiveness of the tools adopted so far in practice reveals, from an analysis that goes beyond substantive law, a more complex reality. In order to understand it, I believe we need to gain more insight into the supranational legal space in which digital platforms operate. The research must start from reality; therefore, I shall investigate international (state) and transnational (companies) practice - recent practice that has, however, quickly (almost 'instantaneously') become common practice - and try to qualify it legally, departing from the mainstream - if not unanimous - assumption in literature, that the solution to the changing phenomenon lies in state regulations and has a regulatory nature. ${ }^{6}$

3 W. Schuster (2018), Artificial intelligence and patent ownership, Washington University Law Review, 75(4), 1945 et seq.; V. Falce (2018), Copyrights on data and competition policy in the digital single market strategy, Italian Antitrust Review, 1, 38.

4 E. Benvenisti (2018), Upholding democracy amid the challenges of new technology: What role for the law of global governance?, European Journal of International Law, 29(1), 9 et seq.; L. Casini (2018), Googling democracy? New technologies and the law of global governance: afterword to Eyal Benvenisti's foreword, European Journal of International Law, 29(4), 1071 et seq. On this topic see also C. O'Neil (2017), Weapons of Math Destruction. How Big Data Increases Inequality and Threatens Democracy, Penguin; J. Bartlett (2018), The People vs. Tech. How the Internet Is Killing Democracy (and How We Save It), Ebury Press, 159; N. Srnicek (2017), Platform Capitalism, Wiley; D. Gerber (1994), Constitutionalizing the economy: German neo-liberalism, competition law and the 'new' Europe, American Journal of Comparative Law, 42(1), 42; A. Hatje (2010), The economic constitution within the internal market, in A. von Bogdandy, J. Bast (eds), Principles of European Constitutional Law, 2nd edn, Hart, 590-591, where it is further remarked that the concept of economic constitution is the 'engine' of the EU integration process (593); A. Gerbrandy (2019), Rethinking competition law within the European economic constitution, Journal of Common Market Studies, 57(1), 128.

5 N. Tusikov (2018), Chokepoints: Global Private Regulation on the Internet, University of California Press; M. Rioux, K. Fontaine-Skronski (eds) (2015), Global Governance Facing Structural Changes. New Institutional Trajectories for Digital and Transnational Capitalism, Palgrave Macmillan; H. Krause Hansen; T. Porter (2017), What do Big Data do in global governance, Global Governance, 23(1), 31-42; M. Campbell-Verduyn (ed.) (2018), Bitcoin and Beyond: Cryptocurrencies, Blockchains, and Global Governance, Routledge.

$6 \quad$ I have tried to point out in other works that more complex explanations are also more compatible with a coherent interpretation of the reality in the making. Namely, I questioned the assumptions from which scholars generally start, i.e. that the regulation of these markets is the goal of governments and institutions; that digital platforms operate in relevant contestable markets; that the current regulatory matrix is suitable and adequate, with appropriate measures, to foster market developments: see: F. Bassan (2019), Potere dell'algoritmo e resistenza dei mercati. La sovranità perduta sui servizi, Rubbettino. That (part of) the solution can be a non-state one and there is room for international organizations, E. Benvenisti explains in Upholding democracy amid the 
The study of the consequences of the digital revolution requires us to be more radical: we need to focus on what constitutes the subjectivity of these new dominant protagonists of the international economy. It is a classic topic, approached with classic research tools; the subject of the research, however, is totally new and the results can be surprising.

This research develops as follows.

The first chapter starts from the urgent need to bring the ecosystem of digital platforms back to a state of unity. I start with the terminology, by providing a definition of digital platforms that allows us to narrow the perimeter of the research (section 1$)$.

The definition serves the purpose of illustrating the current ecosystem of digital platforms. I use the same tools and follow the same perspectives from which states and regulators are currently facing the digital evolution. It is not my intention to delve into all of these issues, each of which would require several monographic studies. My intent is rather to bring approaches, tools and practices back to the system, and to investigate in two directions.

The first consists in understanding whether the actions (and reactions) of states and regulators towards digital platforms show contradictions, or have a lowest common denominator, or are at least consistent with each other and, in the latter case, whether such consistency is in turn consistent with the real evolution of digital platforms.

The second direction consists in understanding whether a line of continuity or at least of consistency can be identified also in the errors, if any, made in approaching the digital evolution that, while not revolutionary in itself, is the basis of a revolution, both in individual relations and in the relations between states, international organizations and multinational companies.

Therefore, I review the regulatory profiles (section 2), focusing my analysis on the European Union approach, which represents the most advanced frontier of market intervention for the defence (or the development, depending on the approach) of continental European welfare, which Brexit has now freed from compromises with British welfare.

The digital revolution is part of a European regulatory evolution that was already fast and that the pandemic has further accelerated; the typical 'perfect storm', where the effectiveness of the interventions is difficult to predict and can only be assessed a posteriori. Nevertheless, the European Union (EU) cannot afford the regulatory inertia that this situation would impose. Therefore, by means of regulations, the EU tries to take a stand on the global scene, recovering its disadvantage at industrial level.

challenges of new technology: What role for the law of global governance?, in (2018) European Journal of International Law, 9-82. 
In the reform of competition rules (section 3) the difference between the European and the US approach towards digital platforms grows bigger. The ineffectiveness of the traditional tools of antitrust law (in the US) and competition law (in the EU) has led the United States to take action towards possible break-up measures, and the European Union towards 'regulated competition', with which it attempts to promote competition through the typical instruments of regulation ex ante. Hybrid competition, actually.

The digital evolution is based on the control of data and the ability to manage it (section 4). Data protection thus becomes a parameter of regulatory effectiveness. Again, the two prevailing models (US and European) diverge. The reason lies in the different cultural approach, of course, but also in the different balance of interests between market freedom and individual rights (no longer consumer rights only). The European regulation imposes a ladder, the rungs of which are based on the principle of proportionality. Already at the core of many cultures, the European Union principles have become global standards (via the Brussels effect) and have also imposed themselves on digital platforms. These, by transforming risks into opportunities, have made them their own, not merely by integrating them into their business but also by using them to develop and protect it.

The opposite approach guides the two sides of the Atlantic as regards the effects of the evolution of digital platforms on democratic principles, with freedom of expression in the foreground (section 5). Here too, the reason lies in constitutional foundations and traditions, but also contingent events: the Trump 'saga' has led public opinion, not only in the United States, to question checks and balances and the prevalence of interests. In the 'tug-of-war' of interests, once the ideology or what remains of it is removed, the debate focuses on how well democratic structures will hold in the face of technological progress. It is an old debate: the dominant narrative has been affirming that globalization is incompatible with democracy since the last decade of the past century. The context, however, is new, because the challenge is no longer the globalization of markets (now classified as 'regional globalization') but that of digital platforms. However, the question remains the same: the compatibility of the phenomena (globalization, digitalization) with the structure and institutions of democracy (which differ according to legal and cultural traditions). But again, the question is still wrong, because it presupposes a Ptolemaic vision of international relations, with the state (indeed, the democratic state) at the centre, which is incompatible with the reality of the evolution of both trade and technology.

The temptation to manage new phenomena using tools that do not have the typical limits of legal tools (e.g., territoriality and enforcement) becomes strong. Hence the 'ethical drift', consisting of principles considered useful in 'Middle-earth', to territories not reached by the rules (section 6). Yet, ethics 
can only trace a path, on which the road (the rules) must then be built. There is much confusion and misunderstanding here, where law and technology are not parallel worlds but join together and hybridize each other.

The distributed ledger technologies, which allow many different applications (cryptocurrencies, smart contracts, etc. ...) complicate the scenario even further (section 7). They are themselves ecosystems, in addition to those of digital platforms and those of artificial intelligence, and raise questions as to which law would be applicable at the intersection of systems, when digital platforms use artificial intelligence, or blockchain, or both (in the latter case, the intersection is between three systems).

I shall first look into the differences in the approaches, tools and perspectives, to ask whether all these interventions (or non-interventions) in the market, and the ensuing debates, are consistent with the definition of digital platform that we have suggested and with the reality of its evolution (section 8 ). The unity of the platform as an ecosystem, on which engineers and economists now agree, produces effects that states and regulators seem not to have really taken note of.

The unity of the ecosystem, on a legal level, translates into order. Private legal systems are numerous and have been investigated for at least a century. If we accept - as I believe is appropriate - this shifting of the platform from an ecosystem (which qualifies its action on the market) to an order (which identifies its institutions and powers) we can lay the foundations of a unitary approach, which is still missing and, seemingly, most needed.

The second chapter starts from these assumptions and investigates whether digital platforms can qualify as private legal systems, starting from the qualification of digital platforms as transnational companies and their placement within transnational law (section 1).

Compared to transnational companies, however, digital platforms have additional elements that lead to their classification as legal systems (section 2). They exercise regulatory powers when they adopt the behavioural policies of the community of users of which they are composed; executive powers, when they take action to enforce the rules adopted; and jurisdictional powers, when they establish independent dispute resolution systems - de facto, arbitration systems. More refined systems (that of Facebook, for instance) provide for real courts, as well as guarantees and protections similar to those of a state (section 3).

If we add to these elements an autonomous payment system and, potentially, in the near future, an autonomous currency (whether a cryptocurrency, or a stablecoin pegged to one given currency or to a basket of currencies, is of little importance for our purposes), the private ordering of platforms becomes complete and increasingly autonomous, almost independent: in other words, sovereign (sections 4 and 5). 
This is the starting point for a new presentation of digital platforms, for they are multinational companies, but have evolved to the point of constituting real legal systems.

This new presentation follows a dual path. The first path (Chapter 3 ) consists of the relationship between these private systems and the other existing public and private orders. In the first place, state systems are relevant (section 1). The classifications developed in Chapter 1 seem useful here, and particularly the distinction between the platforms' internal and external environments. The legal approach allows us to provide assumptions and justifications for such a distinction. Private international law provides all the tools (starting from renvoi between legal systems) to define and qualify the relationships between digital platforms and states, and shows the ineffectiveness of the regulatory tools presently used, which do not grasp the evolution of the platforms at institutional level.

From another point of view, public international law makes it possible to define the relationship between the private transnational systems of digital platforms and international law. The path is different if one follows either the monist or the dualist approach, but the outcome is the same (section 2). It is no coincidence, therefore, that the most refined tool examined, i.e. Facebook's Oversight Board, supplements its internal norms not by referring to state laws but to the principles of public international law, beginning with those on the protection of human rights.

The relationship between the platforms' private transnational systems and the lex mercatoria (section 3) - when the latter should be recognized as an order, which is still the subject of heated and articulated controversies - exists when the lex mercatoria evolves (via arbitration awards or generally accepted principles and practices (GAPP)) by applying the internal policies of digital platforms. It is a predictable development, if the principles and paths of the European regulatory circle apply (Chapter 1, section 2).

It is therefore not only possible but, I believe, entirely probable that another question arising is the relationship between one transnational digital order and another (i.e., between two digital platforms). The more the lex mercatoria develops in terms of digital systems, the more these will be able to integrate and share rules and principles, not just protocols and standards (Chapter 3, section 4).

The second path (Chapter 4) concerns the possible qualification of digital transnational private legal systems as subjects of law. Their being transnational is beyond doubt. But are they also subjects of international law? Again, the path is different if one follows the monist theories based on decentralization (section 1) or the dualist theories based on the pluralism of legal systems (section 2). The outcome here appears different at first sight, since the subjec- 
tivity of digital transnational legal systems seems admissible in international law according to the monist approach, but is denied by dualist theories.

This divergence, however, becomes merely apparent if we follow the dualist approach of Arangio-Ruiz, which defines the subjects of international law as de facto 'powers' (section 3), as they both exist and are independent. For Arangio-Ruiz, natural and legal persons are not subjects of international law. Conversely, international organizations (among others) are subjects of international law. They have internal law (which governs relations within the organization) and external law (which governs relations between the international organization and other subjects of international law). Arangio-Ruiz defines the internal law of international organizations as international interindividual law.

Well, the analogy with digital platforms is evident. They too are powers, like international organizations, and constitute a legal system whose law, which applies to the community of users, is 'international interindividual'. Digital platforms can then also qualify as subjects of international law, insofar as they participate in the interstate law of international relations.

This conclusion, on closer inspection, coincides with a branch of evolution of the theory of global law, defined as the law of non-state governance communities.

These findings lead to the concluding chapter, Chapter 5. It can be affirmed, based on the evidence of Chapter 2 and the conclusions drawn in Chapter 4, that there is a global law of digital platforms.

Compared to this, the regulatory matrix used so far by states to tackle the rise of digital platforms is inadequate, for the reasons illustrated in Chapter 1, and because it does not take into account the legal evolution of digital platforms highlighted in Chapters 2 and 4 (Chapter 5, section 1).

Therefore, the need for a new paradigm arises: a new matrix equipped with new tools. The playing field must shift from the current matrix of market regulation - which governs the relationships between companies and between states and companies - to that of negotiation, which presupposes a relationship between peers. This evolution does not conflict with what is already considered, in the European Union, to be the main evolution of regulation: self-regulation (the 'law of digital platforms'), which then becomes co-regulation via negotiation with independent authorities and national governments.

If the paradigm change that I propose is consistent with the current developments of the institutions and of the markets, then the tools of uniform law that are emerging - the negotiation between private and public norms and the codification of private law - become central. We may see such codification as the first phase of regulation (self-regulation) or, shifting our analysis to the level of legal systems, the internal law of platforms: what Arangio-Ruiz calls international interindividual law (section 3). 
The centrality of these tools is not new: during the 1980 s, the codification of uniform law was already one of the assumptions and premises of globalization, which developed strongly in the 1990s. They will be useful again, in the different form that I am suggesting here, to regulate digital globalization too, which is no less rapid than the general globalization of the 1990s, but bears implications that go far beyond the markets.

The new paradigm is described in the last section of the chapter (section 4). 